\title{
Analysis of the NASH Efficiency Indicators in Brazilian Federal University Hospitals via Business Intelligence
}

\author{
Carlo Alessandro Melo Noce \\ Post-Graduation Programm in Biomedical Engineering, \\ University of Brasilia at Gama, Brazil \\ alessandro_mn@hotmail.com
}

\author{
Georges Daniel Amvame Nze \\ Electrical Engineering Department, \\ Institute of Technology, University of Brasilia, Brazil \\ georges.amvame@gmail.com
}

\author{
Lourdes Mattos Brasil \\ Post-Graduation Programm in Biomedical Engineering, \\ University of Brasilia at Gama, Brazil \\ lmbrasil@gmail.com
}

\begin{abstract}
The hospital area is constantly in need of care and attention. Because of its urgencies, it has vulnerabilities and risks that hinder the quality of hospital management. Technological management tools are effective in improving processes and strategic administration because they provide information reliability. The aim of this work is to propose to the Brazilian's Federal University Hospitals (BFUHs) and to the Brazilian Hospital Services Company (BHSC) the use of an open source Business Intelligence (BI) tool, Pentaho, to analyze the efficiency of Hospital Indicators (HIs) and to support the clinical decision- making. This paper describes BI and Pentaho, as well as the main points of the efficiency documentations established by the National Agency of Supplementary Health (NASH), with emphasis on the HIs: Hospital Occupancy Rates (HORs) and Averages Length of Stay (ALSs). The Pentaho does the data extraction and the transformation, as well as loading them into the Data Warehouse $(\mathrm{DW})$, all based on a relational database from BHSC. After that, dimensional cubes are created for the generation of graphic panels in dashboards. Most BHSC hospitals are not yet adequately using their operational beds and neither managing correctly the average length of hospitals patients stay, being outside the goals established by NASH. Several steps are taken to achieve efficient hospital administration. However, the joint working of Information and Communication Technologies (ICTs) solutions with the health area and its standards provides a major step towards efficient hospital management.
\end{abstract}

Index Terms-BHSC, BI, hospital management, ICT, NASH.

\section{INTRODUCTION}

The 21 st century is providing humanity with the experience of the Information and Communication Technology (ICT) era in society. Its increasing and steady advancement is bringing diverse benefits to everyone who uses it. The health area is one of the most benefited, with improvements in access to health services, quality of care and productivity of the health system. Hospitals are complex environments that need technological solutions to provide their services. Their demands are always urgent and they constantly need special attention and intensive care. Therefore, it is essential to equip these establishments with technologies that assist health professionals in the diagnosis of diseases and in the treatment of patients.

In recent years, science and technology have provided a wide range of tools to health professionals. This variety of products and development of new medical devices or solutions is due, in part, to the competitiveness between companies. The growth of activities based on Telemedicine and the improvement of the treatment of patients create in the health sector great demand for technological resources [1].

As in the most diverse sectors of society, the use of ICT generates important reflexes in health, especially about the quality of citizen service, efficiency in the management of health facilities and the intelligent use of available information. [2].

Hospital Management is the area that provides planning, control, coordination, organization, evaluation and maintenance of health care environments, with a strategic focus on achieving better results. It directs the flow of activities using processes that have been defined through laws, regulations, ordinances, manuals and policies, to integrate and standardize in a managerial way each of the necessary steps that involve the provision of health service to society.

Hospitals are complex organizations, and their proper management is a major challenge. This complexity stems from the multiplicity of services that exist within this type of organization, which contribute to the achievement of the purposes that this institution proposes. This level of complexity may be even greater or less, per the availability of a product that is indispensable for management: "information" [3].

In general, many medical errors are due to the lack of information that were to be obtained at the time of care, leading to misdiagnoses and problems of drug incompatibilities. This becomes especially serious in emergency situations where rapid action is necessary and the professionals may not have skills or be unfamiliar with the patient's health history [4].

Today, ICTs have innovative solutions for managing information. These technological tools provide adequate information management, mapping the flow of data across the different sectors of a company, to support the development of daily activities and decision making in the business environment.

As an improvement of this management, a new stage arises, the need to manage the cluster of information, that is, to realize the administration of knowledge. Knowledge management is a set of strategies for creating, acquiring, sharing and using knowledge assets, as well as establishing flows that guarantee the necessary information in the appropriate time and format, to aid in generating ideas, problem solving and decision making [5].

In this way, a technological solution that is already being used by several ICT companies for information and knowledge management and process improvement is known as Business Intelligence (BI). BI is a set of techniques and tools that help companies to make intelligent decisions through data and information obtained by various ICT systems. BI can also be defined as the process of collecting, organizing, analyzing, sharing, and monitoring information that supports decision making in business affairs. That is, to group and transform 
data from several sources without any type of relationship, in consolidated information and made available in real time and to be easily manipulated by the strategic management of any corporations. BI offers a powerful mechanism system that assists the manager in supporting decision making [6].

Nowadays, companies that do not use BI may be slowing down and therefore making bad decisions because they cannot see the benefits of the solution and do not understand how such tools can contribute to their decision-making process. In some cases, they even have the analytical potential, but do not use the appropriate tools for analysis [7].

The growing need for reliable data and indicators for decision-making, lack of information management and collaboration, difficulty to access information as quickly as possible, and high spending on technologies that do not meet the demands of health care are relevant factors for hospitals, clinics and laboratories to change and adopt as soon as possible the strategy guided by hospital management and ICT management, and in this area, supported by BI.

The National Supplementary Health Agency (NASH), a regulatory agency linked to the Brazilian Ministry of Health $(\mathrm{MH})$, is responsible for the health insurance sector in Brazil. It has a Qualification Program for Health Service Providers (QPHSP) that aims to stimulate the qualification of health service providers in supplementary health and increase the availability of information.

During the planning stage of QPHSP, 26 essential Hospital Indicators (HIs) were defined within the scope of its Management Committee (MC). These indicators provided improvements in health service delivery, with six areas of action [8]:

- Access - This field has two documents that deal with reception with risk classification and waiting time in the emergency and emergency;

- Centralization in the patient - This field has two documents that describe about customer satisfaction and customer manifestation monitoring.

- Effectiveness - This field has five documents that address the implementation of guidelines and clinical protocols and mortality rates;

- Efficiency - This field has eight documents describing operational occupancy rates and average length of stay;

- Equity - This field has two documents that deal with accessibility to the disabled and measures to guarantee, in the attendance, the priority to the vulnerable; and

- Safety - This field has seven documents that deal with the incidence of bloodstream infection rates associated with Central Venous Catheter (CVC) in the Intensive Care Unit (ICU), ICU/CVC utilization rates, and compliance with surgery standards Safe.

These indicators provide fundamental subsidies for obtaining a standardization and control in health care, favoring and facilitating the implementation and execution of hospital management in health settings. However, the HIs explored in this study refer to the Operational Occupancy Rate (OOR) and the Average Length of Stays in hospitals (ALSs) of the Efficiency domain, which evaluates the degree of beds utilization in a Brazilian hospital and the average length of stay (in days) of a patient in the hospital.

The Brazilian Hospital Services Company (BHSC) is a public company linked to the Brazilian Ministry of Education (ME) and manages up to the present date, in its network of hospitals, 39 Federal University Hospitals (FUHs) of the 50 that exist in all Brazilian territory [14]. BHSC, in its Manual of Concepts and Nomenclatures of Hospital Beds, adopts these
HIs of efficiency in care planning service and describes them as Hospital Occupancy Rate (HOR) and Averages Length of Stay (ALSs) in hospitals: these nomenclatures will be adopted in this work. NASH efficiency HIs are important for hospitals because they provide efficient management of the operational beds and average length of stay (in days) in which a patient stays in the hospital, increasing the supply of beds to the health system and controlling the permanence (entry and exit) in patients' beds [30].

This paper aims to propose to Brazilian's FUHs (BFUHs) and BHSC the use of an open source BI tool, Pentaho, to analyze the application of NASH efficiency HIs and support to clinical decision making. In this way, in section II is carried out the theoretical foundation, being analyzed three related works. In section III, in materials and methods, the BI process is done by collecting and analyzing data from the BHSC relational database and transforming that data into managerial information. Moreover, in section IV the results obtained are presented, through graphical and statistical panels generated by Pentaho, the main contribution being the possibility of visualizing in real time the efficiency HIs.

\section{RELATED WORKS}

The main related works are listed below and commented on in Table I.

A. Information system applied to hospital management: a situational overview of the Mato Grosso (MT - Brazil) mid-north region [3].

B. Intelligence in public health organizations: solutions and strategic information for management [9].

C. TICE.Healthy: Integration of ICT solutions for Health and Quality of Life [10].

\begin{tabular}{|c|c|c|c|}
\hline \multirow[b]{2}{*}{ Table } & \multicolumn{3}{|c|}{ Worles } \\
\hline & A & B & C \\
\hline Authors & $\begin{array}{l}\text { P. C. Souza, } \\
\text { A. Bendit, L. } \\
\text { S. Medeiros, } \\
\text { R. S. Souza e } \\
\text { D. Teixeira }\end{array}$ & L. C. M. Frota & $\begin{array}{l}\text { Virginie Felizardo, } \\
\text { paula Sousa, Daniel } \\
\text { Oliveira, Celina } \\
\text { Alesandre, Nuno C. } \\
\text { Garcia, Nuno M. } \\
\text { Garcia }\end{array}$ \\
\hline Year & 2012 & 2009 & 2014 \\
\hline Sample & $\begin{array}{l}\text { Hospitals in } \\
\text { the mid-north } \\
\text { region of Mato } \\
\text { Grosso (MT- } \\
\text { Brazil). }\end{array}$ & $\begin{array}{l}\text { Organizations } \\
\text { of the } \\
\text { Brazilian } \\
\text { Indirect } \\
\text { Administratio } \\
\text { n }\end{array}$ & $\begin{array}{l}\text { TICE Healthy } \\
\text { Project, And its } \\
\text { Metabolic. Care } \\
\text { subproject. }\end{array}$ \\
\hline Goals & $\begin{array}{l}\text { To investigate } \\
\text { the siruation of } \\
\text { these hospitals } \\
\text { regarding the } \\
\text { use of IS to } \\
\text { support } \\
\text { management. }\end{array}$ & $\begin{array}{l}\text { Identify in the } \\
\text { literature and } \\
\text { in these } \\
\text { organizations } \\
\text { the limits and } \\
\text { possibilities of } \\
\text { the adoption } \\
\text { of BI and IC } \\
\text { for } \\
\text { DATASUS. }\end{array}$ & $\begin{array}{l}\text { Describe this project } \\
\text { and discuss its } \\
\text { subproject in more } \\
\text { detail. }\end{array}$ \\
\hline Methodology & $\begin{array}{l}\text { Case study } \\
\text { with } \\
\text { quantitative } \\
\text { approach. }\end{array}$ & $\begin{array}{l}\text { Use of } \\
\text { qualitative } \\
\text { approach. }\end{array}$ & Literature review \\
\hline Results & $\begin{array}{l}\text { IS with } \\
\text { administrative } \\
\text { information: } 8 \\
\text { hospitals: IS } \\
\text { with clinical } \\
\text { information: } 1 \text {; } \\
\text { IS with cost } \\
\text { management } \\
\text { information: } 1 \text {. }\end{array}$ & $\begin{array}{l}\text { The use of IC } \\
\text { and BI in the } \\
\text { organizations } \\
\text { is incipient; } \\
\text { however, it } \\
\text { can be } \\
\text { incorporated. } \\
\text { There are few } \\
\text { experiences } \\
\text { applied to } \\
\text { health. }\end{array}$ & $\begin{array}{l}\text { Results at: } \\
\text { hmps } / / \text { levida.pt/. }\end{array}$ \\
\hline $\begin{array}{l}\text { Common } \\
\text { Points }\end{array}$ & $\begin{array}{l}\text { Use of IS to } \\
\text { support } \\
\text { hospital } \\
\text { management. }\end{array}$ & $\begin{array}{l}\text { Use of BI in } \\
\text { the health to } \\
\text { support } \\
\text { hospital } \\
\text { management. }\end{array}$ & $\begin{array}{l}\text { Integration of ICT } \\
\text { solutions for Health. }\end{array}$ \\
\hline Differences & $\begin{array}{l}\text { Does not use } \\
\text { BI. Does not } \\
\text { perform any } \\
\text { HI studies. }\end{array}$ & $\begin{array}{ll}\text { Does } & \text { not } \\
\text { perform } & \text { any } \\
\text { HI studies. }\end{array}$ & $\begin{array}{l}\text { Does not use BI } \\
\text { Does not perform } \\
\text { any HI studies. }\end{array}$ \\
\hline
\end{tabular}




\section{MATERIALS AND METHODS}

The objective of this work is to analyze the application of HIs in BFUHs by means of BI. An analysis of data between hospitalized patients and active beds (for the calculation of HORs) and inpatients and outpatients (for ALSs). Using Pentaho, a free BI tool, this work will provide these hospitals an efficient and intelligent management of data obtained from relational databases. As well as providing adequate HORs and ALSs dashboards analytics, BHSC will be able to explore the best technical and strategic decision making to reduce any kind bad in BFUHs.

\section{Step 1: Analyze the BI and Pentaho framework}

A BI can be structured as exemplified in Figure 1 [11]. Data are collected from a company's relational databases (business and transactional systems) to be transformed into information and start the BI process through the Extract, Transform and Load (ETL) step. This information is stored in a Data Warehouse (DW), subdivided into DataMarts (DMs), and thus used in dashboards capable of providing key information on the company's current situation, supporting senior management in the process of technical and strategic decision- making.

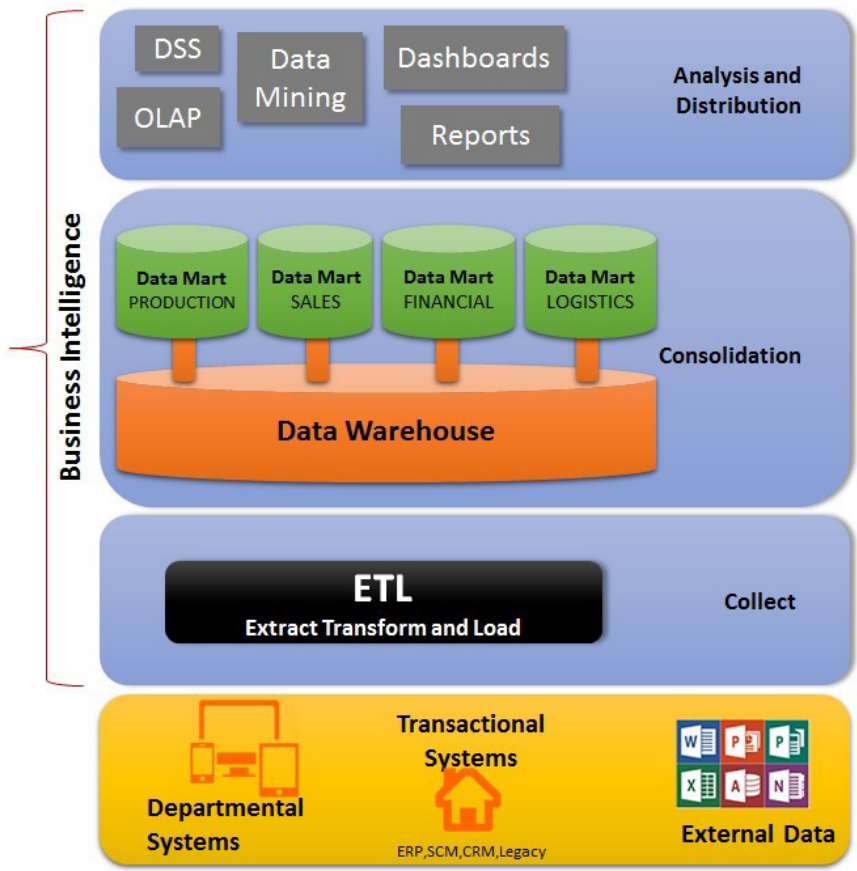

Fig. 1. Structure of the architecture of a BI. Adapted from [11].

Pentaho is an open source tool that has a suite of applications to perform each of the steps required to implement BI. In this work, we used the following applications from this tool [12]:

- Pentaho Data Integration (PDI - Kettle): application that performs the ETL to load the information in the DW;

- Pentaho Schema Workbench (PSW - Mondrian): an application that creates the dimensional cubes of analytical processing in real time, Online Analytical Processing (OLAP);

- Pentaho Administration Console (PAC): application that manages the solution, creating for example users and their access profiles;

- Pentaho User Console (PUC): an application that provides users with access to view dashboards; and

- Community Dashboard Editor (CDE): a plugin that allows the creation and generation of dashboards.

\section{E. Step 2: Perform data collection from the relational}

database.

A relational database is a database that has structured data, but it is separate and there is no interaction between its tables. In this study, a relational database was obtained from data published on the Internet [13] by BHSC. These raw clinical data are registered in the University Hospital Management Application (UHMA). All data, presented here were analyzed from April 2015 to May 2015. These data are related to the number of patients hospitalized in each BFUH, the number of active beds in each BFUH and the number of outpatients in each BFUH.

\section{F. Installation of Pentaho, transformation and loading of} data and generation of OLAP cubes.

Pentaho was installed in a virtual machine (VM) using the Oracle VM VirtualBox [15] open source tool and the Linux operating system - Ubuntu Server [16] with the configuration of a PostgreSQL database [17], an Apache web server [18] for viewing dynamic pages and the PHP programming language [19] for dynamic page programming.

A dimensional model is a technique used in DW for grouping specific information and prepared to analyze any information in more than one dimension. This model defines the dimension tables that have a set of information to be worked in the BI, and the fact table that has the dimension's keys and the metrics/measures for the dimensional analysis [20].

Figure 2 shows the schematic of the star schema model, since the dimensional tables that compose it are directly related to the fact table.

\begin{tabular}{|l|}
\hline \multicolumn{1}{|c|}{ DIM_GENERAL_OCCUPANCY_EXTRACT } \\
\hline occupancyid_sk \\
\hline fuh \\
\hline hospital_unit \\
\hline hospitalizations \\
\hline beds \\
\hline occupancy_rate \\
\hline current_time \\
\hline
\end{tabular}

\begin{tabular}{|l|}
\hline \multicolumn{1}{|c|}{ FACT_GENERAL_OCCUPANCY_EXTRACT } \\
\hline occupancyid_sk \\
\hline dateid_sk \\
\hline Metrics/Measures \\
Quantity - hospitalizations/beds/occupancy_rate \\
\hline
\end{tabular}

\begin{tabular}{|l|}
\hline \multicolumn{1}{|c|}{ DIM_DATE } \\
\hline dateid_sk \\
\hline date \\
\hline year \\
\hline month \\
\hline day \\
\hline
\end{tabular}

Fig. 2. DW dimensional model for BFUHs General Occupation Extract. Source: Authors

The dimensional table dim general occupancy extract (fields: primary key, acronym of $\mathrm{FUH}_{\mathrm{H}}$, hospital units, quantitative of inpatients and active beds, occupancy rate and current time - date). The dimensional table dim_date (fields: primary key, date, year, month and day). Moreover, the fact table,fact_general_occupancy_extract (fields: primary keys of the dimensional tables and metrics/measures of the quantitative of hospitalizations, beds and occupancy rate of BFUH.

There are other dimensional models described in the literature that allow the construction of a database for DW. For example, the snow flake model allows dimensional tables 
to relate to the fact table, but some dimensions relate only to one another. In addition, the constellation of facts model allows multiple fact tables to share dimensions among other tables [20].

Regarding the model, the ETL process was started using the Kettle application. This application made the query in the database obtained from BHSC, extracting only the data regarding the number of inpatients and active beds.

Figure 3 shows through Kettle, the flowchart of the process of extracting, transforming and loading the data in the DW, creating a DM, a dimension referring to the extract of general occupation of the BHUFs. The first object called table input performs the query in the general_occupancy_extract table of the relational database obtained from BHSC. The second object called select values selects the columns of this table to get its data. And the third object called tablet output creates in DW the dimensional table, that is, the DM with the data extracted from the relational table.

Fig. 3. ETL process flowchart of the general occupancy extract from BFUH using Kettle. Source: Authors

Then Kettle was used to create the dim date dimension, which contains the occupancy time data in the BFUHs. Figure

4 shows the ETL process flowchart of this dimension by creating the DM in its DW. It is called General_populate date_dimension_AU.ktr [12], and generates 40,000 date data, starting in the year 1950 and going through 2040. The object dayofweekdescgen groups the relationship of the days of the week and the object monthdescgen groups the relationship of Months. These two objects reference the first 40000days100+ years object that defines the period of years. After this, the data is grouped and the dim_date dimension table is created in the DW or DM.

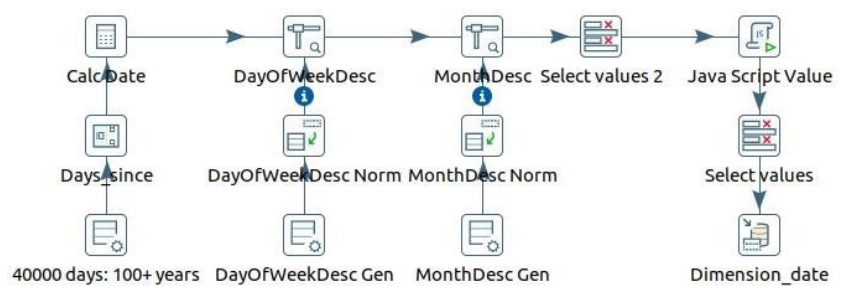

Fig. 4. ETL process flowchart of the occupancy length from BFUHs using Kettle [12]. Source: Authors.

The fact table, fact_table_general_occupancy_extract has been created using Kettle, as presented in the star model of the DW mentioned above. Figure 5 shows the creation chart of the fact table in DW. The first object table input selects the data from the dimensional table general_occupancy_extract, the second object dimension lookup/update get the primary key from the general_occupancy_extract table, the third object database lookup obtains the primary key from the dimensional table dim date, the fourth object select the columns values of these tables to obtain their data.

After completing this step, the OLAP dimensional cube was created to cross-reference the information using the Mondrian application. Figure 6 shows this cube, General Hospital Occupancy Rate (GHOR), which obtains the primary key that is in its respective fact table and has three hierarchical levels, the FUH acronym, the service specialty, and the date of analysis. Finally, metrics / measures are defined (number of hospitalizations, number of active beds and GHOR).

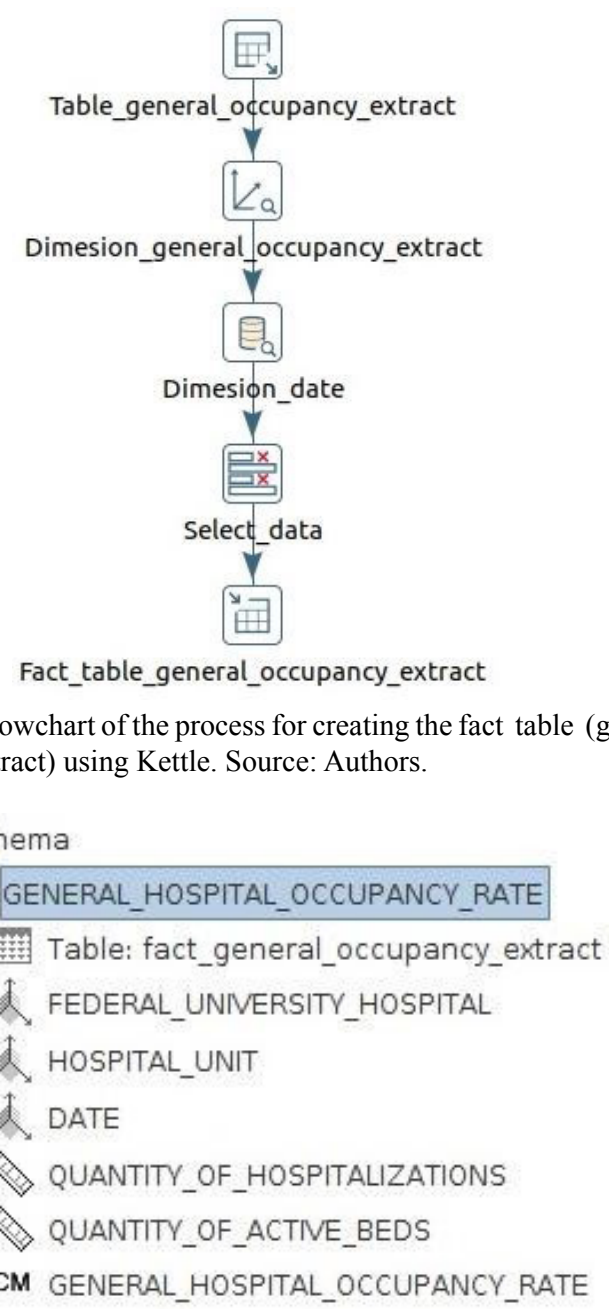

Fig. 6. OLAP Cube - General Hospital Occupancy Rate, generated by Mondrian. Source: Authors

In order to avoid redundancies, the figures referring to the dimensional model, flow diagram of the ETL process dimension tables, flowchart of the process of creation of the fact table and OLAP cube of the other seven efficiency HIs studied were suppressed from this work; because they have the same training structure as the GHOR.

G. Step 4: Study of the General Hospital Occupancy Rate (GHOR)

The NASH efficiency stage indicator 01 (EFFI-S-01) [22] defines the GHOR and the following concepts:

- Patients-day (pd): unit of measure that represents the care provided to an inpatient during a hospital day;

- Operational day-beds (odb): unit of measure that represents the availability of a hospital bed for a hospital day;

- It is recommended an occupancy rate between $75 \%$ and $85 \%$; The occupancy rate above $85 \%$ is related to the increase in adverse events;

- The occupancy rate below $75 \%$ indicates low utilization and inefficiency in hospital management;

- The goal is to keep the occupancy rate between $80 \%$ and $85 \%$ and the rate should never exceed $100 \%$; and

- The GHOR has a method of calculation that is done by the sum of the number of general patients- day in the period, divided by the sum of the number of active beds-day in the period, times 100, according to Equation 1. 
GHOR $=\frac{\sum \mathrm{n}^{\circ} \text { of general patients-day in the period }}{\sum \mathrm{n}^{\circ} \text { of active beds-day in the period }} \times 100$

H. Step 5: Study of the Maternity Hospital Occupancy Rate (MHOR)

The NASH efficiency stage indicator 02 (EFFI-S-02) [23] defines the MHOR and the following concepts:

- $\mathrm{pd}$, odb, recommendations and goal according to the GHOR documentation; and

- The MHOR has a method of calculation that is done by the sum of the number of patient-days of Maternity in the period, divided by the sum of the number of Maternity's operational beds-day in the period, times 100, according to Equation 2.

$$
\text { MHOR }=\frac{\sum \mathrm{n}^{\circ} \text { of patients-day of Maternity in the period }}{\sum \mathrm{n}^{\circ} \text { of maternity operational beds-day in the period }} \times 100
$$

\section{Step 6: Study of the Adult ICU Hospital Occupancy} Rate (AIHOR)

The NASH efficiency stage indicator 03 (EFFI-S-03) [24] defines the AIHOR and the following concepts:

- pd, odb, recommendations and goal according to the GHOR documentation;

- Intensive Care Unit (ICU): critical area for the hospitalization of severe patients, requiring specialized professional attention in a continuous way, specific materials and technologies necessary for diagnosis, monitoring and therapy;

- Adult ICU: area for the care of patients aged 18 years and over, who can admit patients from 15 to 17 years, if defined in the institution's rules; and

- AIHOR has a method of calculation that is done by the sum of the patients-day numbers of the Adult ICU in the period, divided by the sum of the number of operational beds-day of Adult ICU in the period, times 100, according to Equation 3.

$$
\text { AIHOR }=\frac{\sum \mathrm{n}^{0} \text { patients-days numbers of Adult ICU in the period }}{\sum \mathrm{n}^{\circ} \text { of operational beds-day of Adult ICU }} \times 100
$$

\section{J. Step 7: Study of the Pediatric ICU Hospital Occupancy} Rate (PIHOR)

The NASH efficiency stage indicator 04 (EFFI-S-04) [25] defines the PIHOR and the following concepts:

- pd, odb, ICU, recommendations and goal according to the PIHOR documentation;

- Pediatric ICU: patients care area aged from 29 days to 14 or 18 years, this limit being defined according to the routines of the institution; and

- The PIHOR has a method of calculation that is done by the sum of the number of patients-day of Pediatric ICU in the period, divided by the sum of the number of beds-day of Pediatric ICU operations in the period, times 100, according to Equation 4.

$$
\text { PIHOR }=\frac{\sum \mathrm{n}^{\circ} \text { of patients-days of Pediatric ICU in the period }}{\sum \mathrm{n}^{\circ} \text { of beds-day of Pediatric ICU operations in the period }} \times 100
$$
(GALS)

K. Step 8: Study of the General Average Length of Stay

The NASH efficiency stage indicator 05 (EFFI-S-05) [26] defines the GALS and the following concepts:

- Patients-day (pd): unit of measure that represents the care provided to an inpatient during a hospital day;

- Exits (ex): number of hospital exits recorded in the period of one month, sum of the number of discharges (regardless of reason for discharge), deaths and external transfers occurring in the hospital in a period of one month;

- The goal should be according to hospital stratification. For Porte I hospitals (small size), 2 to 3 days; Porte II (medium size), 3 to 4 days and Porte III (large size), 4 to 5 days of stay; and

- The GALS has a method of calculation that is done by the sum of the number of general patients-day in the period, divided by the sum of the number of general outputs in the period, according to Equation 5.

$$
\text { GALS }=\frac{\sum \mathrm{n}^{\circ} \text { of general patients-day in the period }}{\sum \mathrm{n}^{\circ} \text { of general outputs in the period }}
$$

L. Step 9: Study of the Maternity Average Length of Stay (MALS)

The NASH Efficacy Stage Indicator 06 (EFFI-S-06) [27] defines MALS and the following concepts:

- Obstetric patients-day (opd): unit of measure that represents care provided to an inpatient in Maternity / Obstetrics of the hospital during a hospital day;

- Obstetric Outcomes (ooc): number of obstetric exits recorded in the period of one month. Sum of the number of discharges, deaths and external transfers of obstetric patients occurred in the Maternity / Obstetrics of the hospital in the period of one month;

- The goal is to maintain the average length of stay in Maternity / Obstetrics of 2.3 days; and

- MALS has a method of calculation that is done by the sum of the number of obstetric patients-day in the period, divided by the sum of the number of obstetric exits in the period, according to Equation 6.

$$
\text { MALS }=\frac{\sum \mathrm{n}^{\circ} \text { of obstetric patients-day in the period }}{\sum \mathrm{n}^{\circ} \text { of obstetric exits in the period }}
$$

\section{Step 10: Study of the Adult ICU Average Length of Stay} (AIALS)

The NASH efficiency stage indicator 07 (EFFI-S-07) [28] defines the AIALS and the following concepts:

- pd according to the documentation of GALS and Adult ICU according to the AIHOR documentation;

- Exits (ex): number of internal transfers of Adult ICU for less intensive units, wards or rooms (internal exits) plus hospital exits (discharge, external transfers and deaths) recorded in the period of one month;

- Observation: In case the hospital has specialized ICUs, such as ICU / Coronary Unit, Neurological / Neurointensive ICU, among others that serve adults, patients-day and the internal and hospital exits of these units should be included in the calculation of the indicator;

- The goal is to maintain the average length of stay in the Adult ICU from 4.5 to 5.3 days; and

- The AIALS has a method of calculation that is done by the sum of the number of patients-day of Adult ICU in the period, divided by the sum of the number of internal exits plus hospital exits of Adult ICU in the period, according to Equation 7.

AIALS $=\frac{\sum \mathrm{n}^{\circ} \text { of patients }- \text { day of Adult ICU in the period }}{\sum \mathrm{n}^{\circ} \text { of internal exits }+ \text { hospital exits of Adult ICU in the period }}$

N. Step 11: Study of the Pediatric ICU Average Length of 


\section{Stay (PIALS)}

The NASH efficiency stage indicator 08 (EFFI-S-08) [29] defines the PIALS and the following concepts:

- pd and ex according to the documentation of the AIALS, ICU according to the documentation of AIHOR and Pediatric ICU according to the PIHOR documentation;

- The goal is to maintain the average length of stay in the Pediatric ICU from 7.4 to 9.9 days; and

- PIALS has a method of calculation that is done by the sum of the number of patients-day of Pediatric ICU in the period, divided by the sum of the number of internal exits plus hospital exits of the Pediatric ICU in the period, according to Equation 8.

$$
\text { PIALS }=\frac{\sum \mathrm{n}^{\circ} \text { of patients }- \text { day of Pediatric ICU in the period }}{\sum \mathrm{n}^{\circ} \text { of internal exits }+ \text { hospital exits of Adult ICU in the period }}
$$

\section{RESULTS AND DISCUSSION}

Thus, 16 graphic panels were generated through the CDE plugin. Figure 7 presents the BFUH status dashboard (General Hospital Occupation) in April 2015, the number of patients hospitalized per BFUH (Figure 7a) as well as the number of active beds per BFUH (Figure 7b). This panel provides a more adequate view to analyze the situation of each hospitals, making it easier to identify which ones have more and fewer hospitalized patients, as well as which ones have more and fewer active beds. To avoid redundancies, three Dashboards of the Hospital Occupation were suppressed: Maternity, Adult ICU and Pediatric ICU.

Figures 8, 9, 10 and 11 respectively show the GHOR, MHOR, AIHOR and PIHOR dashboard of the BFUHs in April 2015. These graphical panels allow a more appropriate visualization for the analysis of the application of HIs efficiency of each of these hospitals, facilitating the identification of which one is in accordance with the parameters established in the NASH documentation. According to the NASH documentation, these parameters should be between $75 \%$ and $85 \%$ and, those below $75 \%$ or above $85 \%$, are considered outside the ideal range and must be analyzed very carefully.

Per these Figures, it is observed that few BFUHs are in accordance with the NASH target that is $80 \%$ and $85 \%$ of HOR, being necessary that BHSC and BFUHs Senior Management advisors should take appropriate measures to mitigate the problems that are favoring this situation. In Figures 9, 10 and 11 not all hospitals entered the analysis, because these health facilities do not have all care units, in this case: Maternity, Adult ICU and Pediatric ICU.

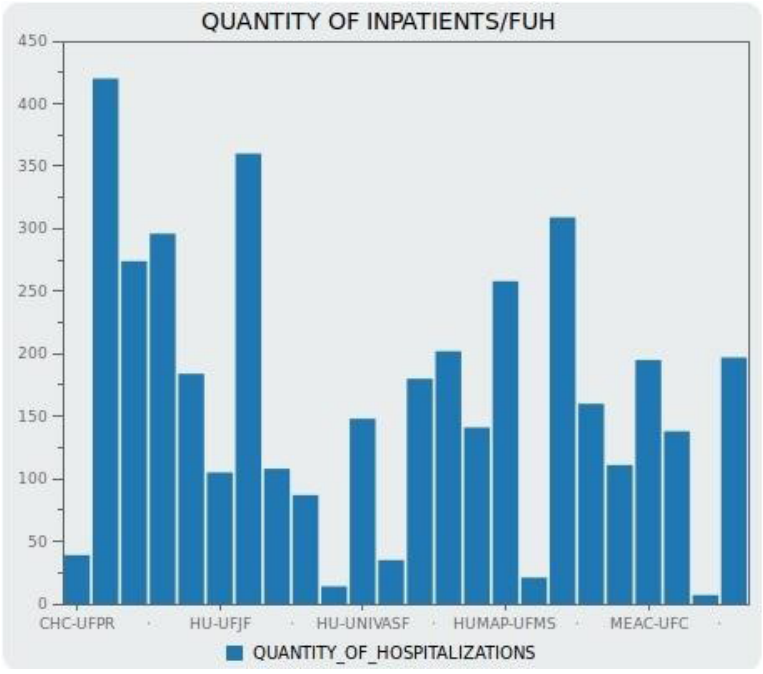

(a)

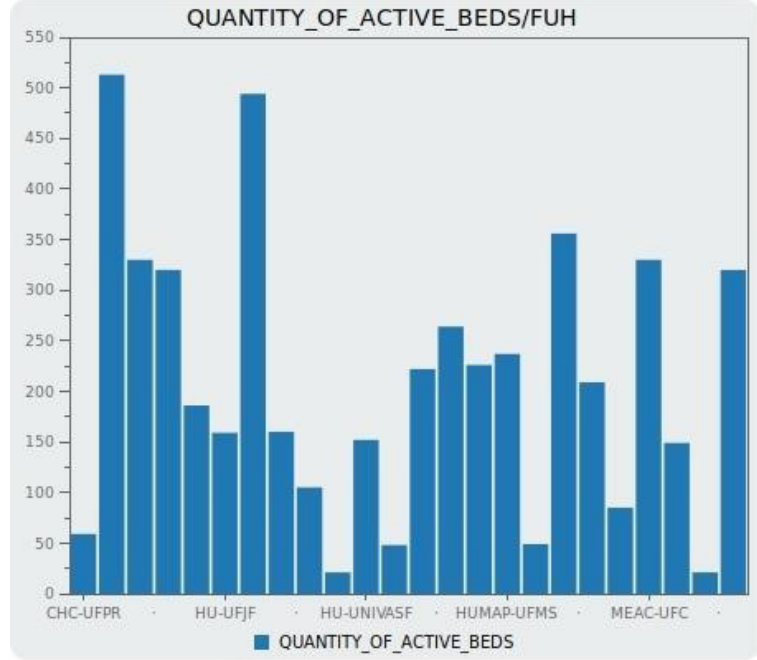

(b)

Fig. 7. Dashboard BFUHs situation analysis in April 2015, referring to the General Hospital Occupancy Rate in terms of quantity of hospitalizations (a) and quantity of active beds (b). Source: Authors.

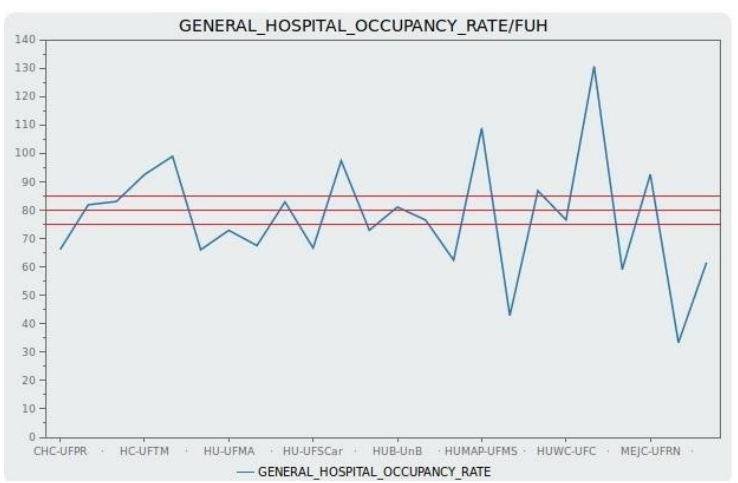

Fig. 8. Dashboard of the BFUHs General Hospital Occupancy Rate in April 2015. Source: Authors

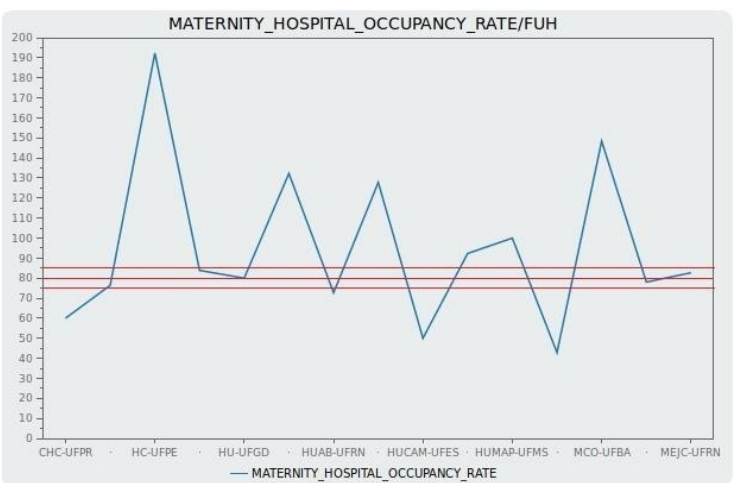

Fig. 9. Dashboard of the BFUHs Maternity Hospital Occupancy Rate in April 2015. Source: Authors.

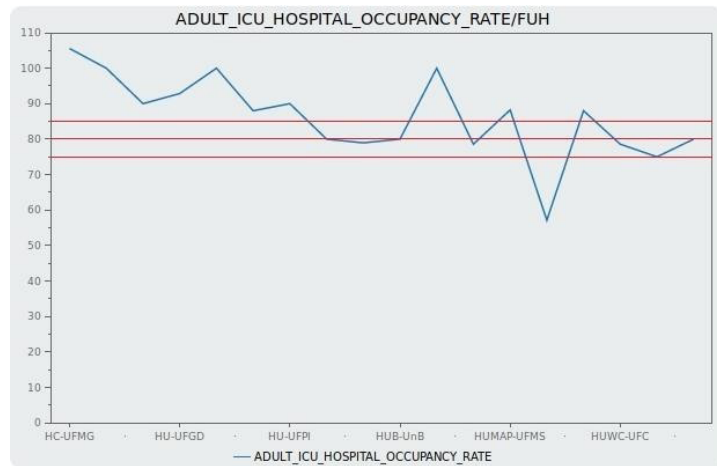

Fig. 10. Dashboard of the BFUHs Adult ICU Hospital Occupancy 
Rate in April 2015. Source: Authors.

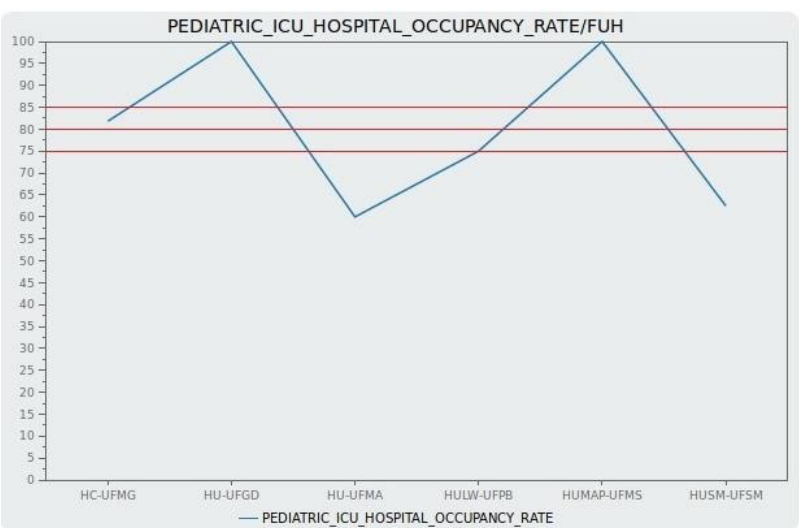

Fig. 11. Dashboard of the BFUHs Pediatric ICU Hospital Occupancy Rate in April 2015. Source: Authors.

Figure 12 shows the BFUHs status (General Stay) dashboard in May 2015, number inpatients per BFUH (Figure 12a) and number of exits - discharge, death, and external transfers per BFUH (Figure 12b).

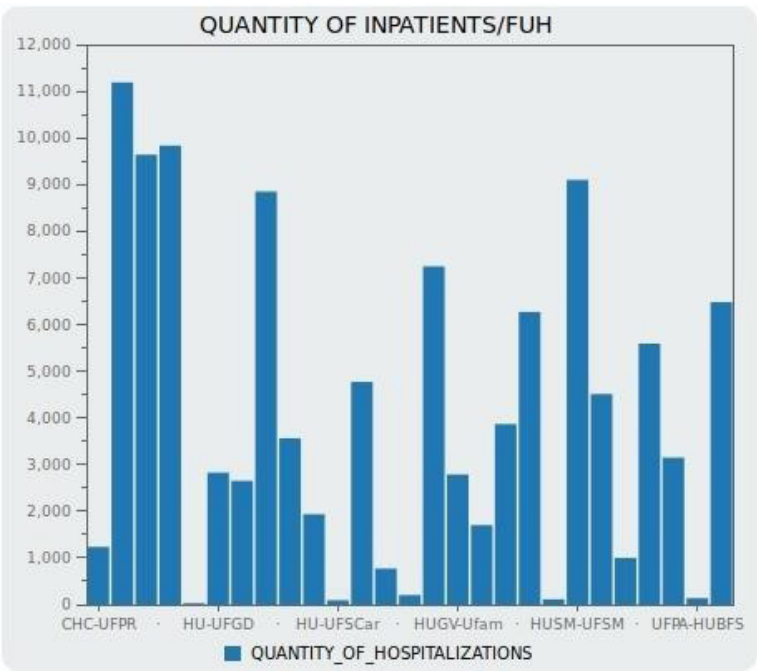

(a)

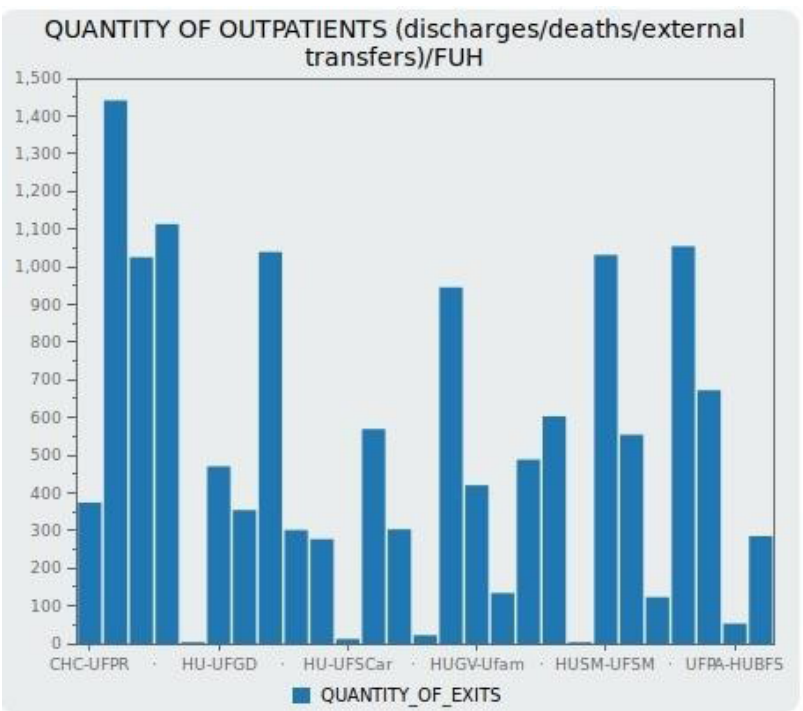

(b)

Fig. 12. Dashboard BFUHs situation analysis in May 2015, referring to the General Average of Stays in terms of quantity of hospitalizations (a) and quantity of exits (b). Source: Authors.
These dashboards provide a better view to analyze the situation of each hospitals, making it easier to identify which ones have more and fewer patients hospitalized, as well as which patients have more and fewer patients. To avoid redundancies, three Stay dashboards were suppressed: Maternity, Adult ICU and Pediatric ICU.

Figures 13, 14, 15 and 16 respectively show the GALS, MALS, AIALS and PIALS dashboard of the BFUHs in May 2015. These graphical panels allow a more appropriate visualization for the analysis of the application of HIs efficiency of each of these hospitals, facilitating the identification of which one is in accordance with the parameters established in the NASH documentation being within or outside the ideal range.

According to these Figures, it is also noted that few BFUHs are in accordance with the NASH target which recommends 2 to 5 days for GALS, 2.3 days for MALS, 4.5 to 5.3 days for AIALS and 7.4 to 9.9 for PIALS. BHSC and BFUHs Senior Management advisors should change their understanding on how to deal with this situation and take appropriate measures to mitigate and even remedy the incidents and problems that are favoring this situation in these hospitals. In Figures 14, 15 and 16 , not all hospitals entered in the analysis, because these health facilities do not have all care units, in this case: Maternity, Adult ICU and Pediatric ICU.

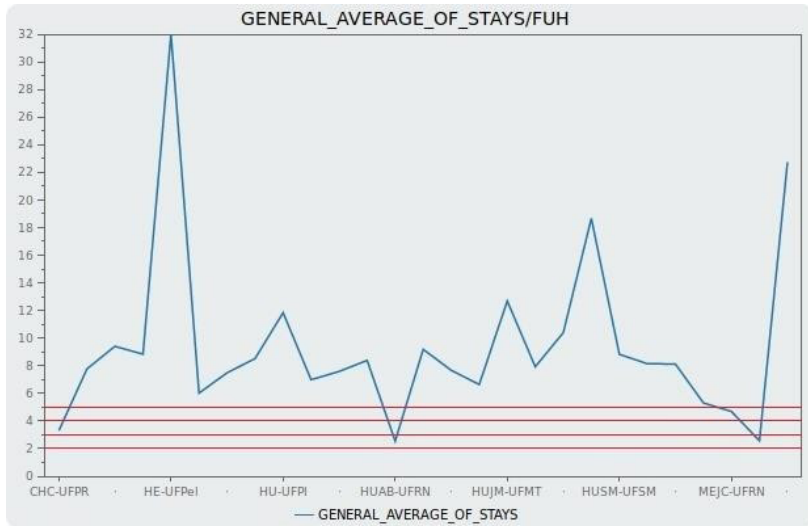

Fig. 13. Dashboard of the BFUHs General Average of Stays in May 2015. Source: Authors.

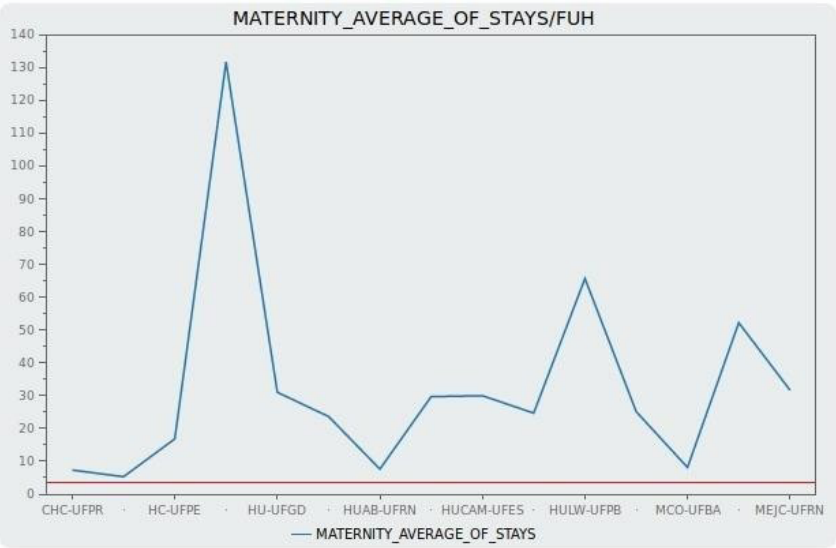

Fig. 14. Dashboard of the BFUHs Maternity Average of Stays in May 2015. Source: Authors

It is then evaluated by the data obtained, for the year under analysis that most BFUHs are outside the NASH recommendations regarding to HORs and ALSs parameters. There are several factors that favored these scenarios, but it is worth highlighting, among others, the latest report from Brazilian Court Union Accounts (CUA) to BHSC [21] on this matter: 
- Lack of specialized health professionals to perform care services; Resistance to replace outsourcers, generating impasses in routine activities;

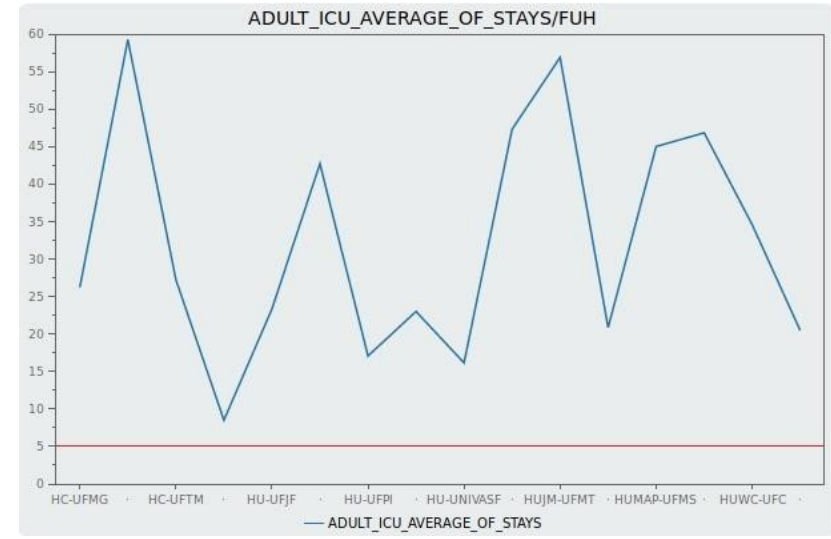

Fig. 15. Dashboard of the BFUHs Adult ICU Average of Stays in May 2015. Source: Authors.

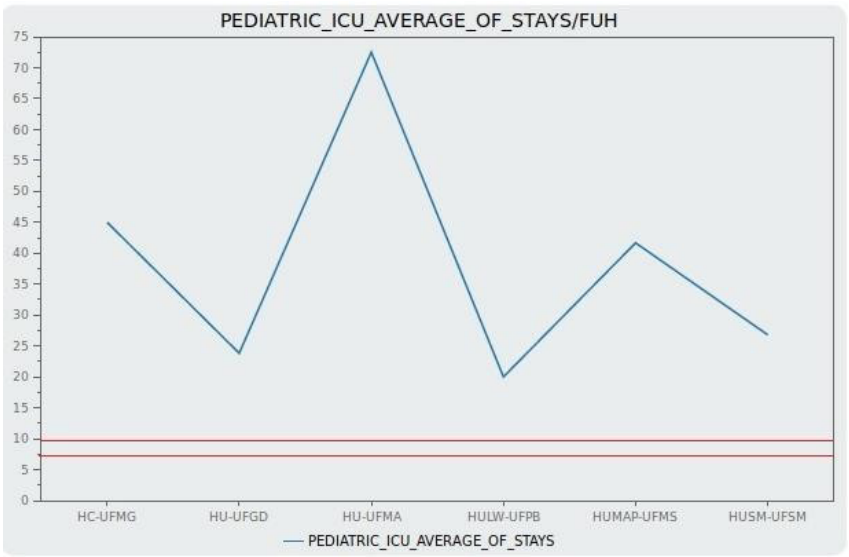

Fig. 16. Dashboard of the BFUHs Pediatric ICU Average of Stays in May 2015. Source: Authors. model;

- Difficulty in implementing the BHSC management

- Inadequate hospital infrastructure to carry out all stages of health care promptly; and

- Lack of planning to deploy and use all resources available to improve any patient care.

Finally, the studies presented in section II have a correlation with this work, since they cover the following subjects: hospital management, ICT and health system, correct use of data information for decision-making and hospital environments. However, what differs this work presented here to the correlates is the analysis of efficiency HIs, HORs and ALSs, which are fundamental for achieving an efficient hospital management, through an ICT solution, allied to BI, to support health professionals. Those should help, in near future, BFUHs and BHSC Senior Management advisors to make secure, accurate and efficient decisions.

\section{CONCLUSION}

This work concluded that the use of an open source BI tool improves information management. However a management without rules of intelligence for the business, won't add anything in favor or to support any decision making environment.

Thus, in order to adequately improve the health care activities and technological resources of the BFUHs, in relation to the occupation of the hospital beds and patients length of stay, this study analyzed the data crossing between inpatients and active beds for the calculation of HORs and the cross- referencing of data between inpatients and outpatients for the calculation of ALSs.

As a contribution, this work proposed the insertion of HORs and ALSs in BIs' dashboards. Hospital managers would then have a real managerial vision of the occupational situation of the hospital beds and patients' stay length, as to seek for a correct technical and strategic decision-making.

As future work, it is suggested the analysis of other hospital indicators provided by the NASH documentation, as well as the creation of tasks to be scheduled for a dynamic execution of NASH's health care parameters into Pentaho.

\section{REFERENCES}

[1] Por que GESITI?, "Gestão de Sistemas e Tecnologias da Informação em Hospitais: panorama, tendências e perspectivas em saúde," Ministério da Saúde, Brasília-DF, 2014, p. 361.

[2] Panorama Setorial da Internet, "TIC no setor de Saúde: disponibilidade e uso das tecnologias de informação e comunicação em estabelecimentos de saúde brasileiros," ano VI, n. 1, Janeiro 2014, p. 1.

[3] P. C. Souza, A. Berndt, L. S. Medeiros, R. S. Souza e D. Teixeira, "Sistema de Informação aplicado à gestão hospitalar: um panorama situacional da região médio-norte mato-grossense," Revista de Administração em Saúde , n. 54, Janeiro-Março, 2012, p. 20.

[4] M. N. Lima, "Saúde Móvel: conceitos, iniciativas e aplicações," $1^{\text {a }}$ ed, Curitiba-PR, Brasil, 2010, p. 9.

[5] M. L. P. Valentim, et al, "O processo de inteligência competitiva em organizações.," DataGramaZero - Revista de Ciência da Informação, Rio de Janeiro-RJ, v. 4, n. 3, 2003, pp. 1-23.

[6] M. M. Laruccia, R. S. P. Da Silva, G. D. Chiarelli, "Discussão sobre o Business Intelligence em empresas de Tecnologia da Informação," Faculdades Integradas Campos Salles - Augusto Guzzo Revista Acadêmica, São Paulo-SP, n. 11, 2013, pp. 140-146.

[7] F. R. Botelho, E. D. Filho, "Conceituando o termo Business Intelligence: origeme principais objetivos," Revista Iberoamericana de Sistemas, Cibernética e Informática, v. 11, n. 1, 2014, p. 55.

[8] ANS, "Agência Nacional de Saúde Suplementar," Disponível em: http://www.ans.gov.br/.

[9] L. C. M. Frota, "Inteligência nas organizações públicas de saúde: soluções e informações estratégicas para gestão," Rio de Janeiro-RJ, s.n, 2009.

[10] V. Felizardo, et al, "TICE.Healthy: Integração de soluções TIC para a Saúde e Qualidade de Vida," Revista Ibérica de Sistemas e Tecnologias de Informação, n. 14, 2014, pp. 17-32.

[11] M. Petrini, M. Pozzebon, F. Meirelles, "Incorporando gestão da sustentabilidade aos sistemas de inteligência de negócios," XXXI Encontro da Associação Nacional de Pós Graduação e Pesquisa em Administração, Rio de Janeiro-RJ, Setembro, 2007, p. 3.

[12] Pentaho, "A Hitachi group company," Disponível em: http://www.pentaho.com/.

[13] Painel AGHU, "Painel de gestão do Aplicativo de Gestão dos Hospitais Universitários

da Ebserh," Disponível em: http://sig.ebserh.gov. br/painel/painelExterno.php?modulo=public/painel Aghu

[14] Ebserh, "Empresa Brasileira de Serviços Hospitalares," Disponível em: http://www.ebserh.gov.br/.

[15] VirtualBox, "Oracle VM VirtualBox," Disponível em: https://www.virtualbox.org/.

[16] Ubuntu, "Ubuntu Server," Disponível em: https://www. ubuntu.com/server.

[17] PostgreSQL, "The world's most advanced open source database," Disponível em: https://www.postgresql.org/.

[18] Apache, "The Apache software foundation," Disponível em: https:/httpd.apache.org/.

[19] PHP, "The PHP group," Disponível em: https://secure.php.net/.

[20] A. R. Nardi, "Fundamentos e Modelagem de Bancos de Dados Multidimensionais," Microsoft Brasil, Outubro 2007. Disponível em: https://msdn.microsoft.com/pt-br/library/cc518031.aspx.

[21] Relatório TCU Ebserh, "Relatório de auditoria operacional da 
Ebserh," Disponível em: http://portal.tcu.

gov.br/data/files/5F/14/53/92/52B31510ED8753152

A 2818 A $8 / 032.519 \% 20 \mathrm{Em} \mathrm{p} \mathrm{r} \mathrm{e} \mathrm{s} \mathrm{a} \% 20$

Servi_os\%20Hospitalares\%20co mp.pdf.

[22] E-EFI-01, “TaxadeOcupação GeralOperacional,”Disponívelem: http://www.ans.gov.br/images/stories/prestadores/E-EFI-01.pdf.

[23] E-EFI-02, "Taxa de Ocupação Operacional Maternidade," Disponível em: http://www.ans. gov.br/images/stories/prestadores/E- EFI-02.pdf.

[24] E-EFI-03, "Taxa de Ocupação Operacional UTI Adulto," Disponível em: http://www.ans. gov.br/images/stories/prestadores/E-EFI-03.pdf.

[25] E-EFI-04, "Taxa de Ocupação Operacional UTI Pediátrica," Disponível em: http://www.ans.gov. br/images/stories/prestadores/E- $\quad$ EFI-04.pdf

[26] E-EFI-05, "Média de Permanência Geral," Disponível em: http://www.ans.gov.br/images/stories/prestadores/E-EFI-05.pdf.

[27] E-EFI-06, "Média de Permanência Maternidade," Disponível em: http://www.ans.gov.br/images/stories/prestadores/E-EFI-06.pdf.

[28] E-EFI-07, “Média de Permanência UTI Adulto," Disponível em: http://www.ans.gov.br/images/stories/prestadores/E-EFI-07.pdf

[29] E-EFI-08,"MédiadePermanênciaUTIPediátrica,"Disponívelem: http://www.ans.gov.br/images/stories/prestadores/E-EFI-08.pdf.

[30] Manual Leitos Ebserh, "Manual de conceitos e nomenclaturas de leitos operacionais," Manual SPA/CRACH/DAS, Empresa Brasileira de Serviços Hospitalares, Ministério da Educação, $1^{\text {a }}$ ed, Brasília-DF, n. 1, Janeiro, 2017, pp. 4-18. 